\title{
Is Plagiarism on the Curriculum of our Medical Schools?
}

\author{
Sushil Dawka ${ }^{1}$
}

Published online: 29 April 2016

(C) International Association of Medical Science Educators 2016

Over 50 Internet articles on plagiarism quote John Milton thus: "Copy from one, it's plagiarism; copy from two, it's research."

This pithy quip did not sound to me like the 17th century English poet who gave the language more words than even Shakespeare. A little investigation showed that this witticism, often misattributed to Milton, was actually said by Wilson Mizner, the American playwright: "If you steal from one author, it's plagiarism. If you steal from two, it's research" [1]. What Milton (himself once accused of plagiarism) actually wrote in Iconoclastes XXIII was, "For such kind of borrowing as this, if it be not bettered by the borrowers, among good authors is accounted Plagiarè" [2]. Both authors were not even saying the same thing; Mizner advised quantity while Milton advocated quality.

Why have so many authors got this wrong? The similarity in names could explain a few, but fifty! (and counting). Obviously, some of these authors have blindly copied the mistake from others without verification. Remarkably, these mistakes occur in articles that discuss plagiarism and have been committed by authors who are all strong proponents of correct attribution.

I use these self-referential misquotes to raise the worrisome issue that while we are all-academics, artists, researchers, writers, composers, comedians, and every one of us - uncompromisingly aligned against plagiarism, we do not always live our sermon. More specifically, I explore the possibility of

Sushil Dawka

sushil.dawka@gmail.com

1 Department of Surgery, Sir Seewoosagur Ramgoolam Medical College, Belle Rive, Mauritius plagiarism being an unintended subject lurking on the hidden curriculum that shadows higher education. The question posed by the title of this piece is not whether we teach medical students about plagiarism but whether we unknowingly train and encourage them to plagiarize.

There are broadly two spheres of academic dishonesty that concern a student: cheating at examinations and cheating on assignments. While cheating in the examination hall is patrolled against and heavily penalized, teachers are less strict or vigilant against dishonesty on assignments. Students are aware of this and, though most would not cheat on a test, they are less hesitant to copy out or download homework. A strong intrinsic deterrent to cheating in examinations is that students are, in effect, cheating against their friends. When working on an assignment, they have no hesitation in copying from sources that, to them, are impersonal pages, not people.

Students are accustomed to indiscriminate sharing of software such as music, video, and e-books. Social networking has fostered the spirit of "generosity," regardless of copyright and legality. The difference between sharing a URL and a download is seen as only one of kilobytes. Some students consider plagiarism as not very different from copying software and music, with possibly a lower inhibitory threshold. Why should they bother with attribution when the original author would never know? After all, they are not doing it for their own entertainment, but as work for the teacher.

Students do a lot of their reading - textbooks or webpages on computers and tablets. Given the cost difference between a printed tree-book (often comparable to a device) and that of an e-book (always cheaper and, if pirated, free), it makes sense to use a digital device, one which also provides internet access and social connectivity. A student reading off a screen is unlikely to pull out pen and paper, or even a keyboard, to make notes: with the digitization of knowledge, "copy and paste" is the modern mnemonic mantra. 
A student submitting copied text as an assignment would need to disguise the source. Some students may rearrange a few words; the ingenious ones do this by web-based translation to and from a second language. Plagiarism detection software is fooled by ingenious ruses like replacing " $\mathrm{e}$ " with a Cyrillic "e" that looks different to software. Filling blank spaces with nonsense text in a white font bloats the word count as well. (A student taught me this!) There is a lot to be said for requiring assignments to be handwritten by the student; they may actually read some of it!

May I now turn the spotlight on us teachers? How meticulously do we attribute our teaching material? We prefer not to clutter up our teaching slides with references and footnotes. We wantonly clip text and images from unnamed textbooks or websites, and at best clump the references on a perfunctory tail-end slide in an indecipherably minuscule font. Admittedly, the ethics and the fair-use policy applicable to lecture teaching are different from that of student submissions and need not match the rigour of scientific article referencing. Still, students learn in class that it is "quite the done thing" to present others' work as your own.

Plagiarism, as theft of ideas and expression, does a lot more than encouraging dishonesty; it asphyxiates originality. Are we subtly promoting plagiarism with examinations and assessment practices that seem designed to discourage creativity? Do we nudge our students towards copying ideas and words instead of thinking them up? We give our students assignments beyond their ability or experience and provide little scaffolding. It is almost as though we expect them to copy off some other source and not let us find out. Each illconceived assignment or project becomes, for the student, an exercise in paraphrasis and a challenge in source concealment. Handouts, question banks, recycled questions, and model answers, all stifle creativity by encouraging (almost requiring) adherence to form. Creativity, in such a learning environment, is deadweight. Students are given the impression that being correct is less about not copying and more about proper referencing; as long as their bibliography reflects the content of their submission, they are safe.

I began this article with conviction; now I am not so sure. Is plagiarism to be fought by fostering good attribution practices or by encouraging originality, given that the former is as tedious as the latter is fickle? Should students' creativity be encouraged at the expense of their conformity? After all, doctors are safest and most efficient when they reason in protocols or make decisions along algorithms; except at the cutting edge of medical research, adventurism or innovation is fraught with risk. Should we emphasize the immorality of plagiarism as greater than the legal infringement of copyright? When even the identification of plagiarism, intended or accidental, is moot, can we ever agree on the nuances in a borderline case? If "There is nothing new under the sun" [3], is the broader concept of plagiarism even valid? Why then is cryptomnesia (mistaking memory for inspiration) not universally admissible in defense?

I feel "plagiarism," the word, has become a circumlocutory genteelism. It sounds like a mild grammatical solecism. We pussyfoot around it as though it were an accidental glitch in some elevated intellectual domain. We handle it as though it were a social faux pas, embarrassing to uncover, best ignored unless glaringly obvious and then, like lettuce on teeth, to be pointed out in a hushed corner.

However, while plagiarism is not always clearly delineated (as with the other less contentious "p" word), "we know it when we see it." Let us then name it and shame it for what it is. Etymologically: kidnapping of phrases and ideas. In sledgehammer terms: theft, piracy, robbery, forgery, and deceit. In our handling of intellectual property, as teachers (and rôle models), we should preach and enforce, apply and exemplify, what was graven in stone a long time ago: "Thou shalt not steal" [4].

Acknowledgments I am grateful to those of my students whose frank opinions sparked this paper.

\section{Compliance with Ethical Standards}

Conflict of Interest The author declares that he has no conflict of interest.

Funding No funding was involved in the preparation of this article. The views expressed here are entirely my own.

\section{References}

1. Bartlett J. Section173.344: John Milton. In: Familiar Quotations, 10th ed. 1919. http://www.bartleby.com/100/173.344.html. Accessed 29 Nov 2015.

2. Platt S. Section: 2077.Wilson Mizner. In: Respectfully Quoted: A Dictionary of Quotations. 1989. http://www.bartleby.com/73/2077. html. Accessed 29 Nov 2015.

3. Ecclesiastes1: 9. In: The Holy Bible: King James Version. 2000. http://www.bartleby.com/108/21/1.html-9. Accessed 29 Nov 2015.

4. Exodus 20:15. In: The Holy Bible: King James Version. 2000. http:// www.bartleby.com/108/02/20.html-15. Accessed 29 Nov 2015. 